\title{
PENINGKATAN KAPASITAS MEDIA SOSIAL INTERPRETASI BUMI PERKEMAHAN PASIR BATANG DESA KARANGSARI KECAMATAN DARMA KABUPATEN KUNINGAN, JAWA BARAT, INDONESIA
}

\author{
Iing Nasihin, Dede Kosasih dan Ai Nurlaila \\ Fakultas Kehutanan, Universitas Kuningan, Indonesia \\ E-mail: iing.nasihin@uniku.ac.id
}

\begin{abstract}
Interpretation activities aim to convey various things related to objects that are interpreted so that visitors can know, understand and participate in maintaining and preserving objects. The progress of the development of information technology has resulted in increasingly growing media so that the opportunity for the use of media for interpretation activities becomes increasingly diverse. The implementation of Interpretation Media Capacity Building for the Manager of Pasir Batang Camping ground is carried out in several stages, namely preparation (interpretation training), analysis of the potential of social media, social media design, and social media management. The results of the PKM activities are the increasing capacity of Kompepar members in interpreting objects and the appeal of social facilities through social media, and the chosen social media is Facebook.
\end{abstract}

Keywords: Pasirbatang, Camping Ground, Interpretation, Media Social, Capacity Building

\begin{abstract}
Abstrak
Kegiatan interpretasi bertujuan untuk menyampaikan berbagai hal terkait objek yang diinterpretasikan sehingga pengunjung dapat mengetahui, memahami dan ikut serta menjaga dan melestarikan objek. Kemajuan perkembangan teknologi informasi menghasilkan media yang semakin berkembang pula sehingga peluang penggunaan media untuk kegiatan interpretasi menjadi semakin beragam.Pelaksanaan kegiatan Peningkatan Kapasitas Media Sosial Interpretasi bagi Pengelola Bumi Perkemahan Pasir Batang dilakukan dengan beberapa tahapan, yaitu persiapan (pelatihan interpretasi), analisis potensi media sosial, desain media sosial, dan pengelolaan media sosial. Hasil kegiatan PkM ini adalah meningkatnya kapasitas anggota Kompepar dalam menginterpretasikan objek dan daya tarik wiasata melalui media sosial, dan media sosial yang terpilih adalah facebook.
\end{abstract}

Katakunci: Pasirbatang, Bumi Perkemahan, Interpretasi, Media Sosial, Peningkatan Kapasitas

\section{PENDAHULUAN}

Bumi Perkemahan (Buper) Pasir Batang yang terletak di Desa Karangsari, Kecamatan Darma Kabupaten Kuningan dan merupakan wilayah Taman Nasional Gunung Ciremai merupakan tempat wisata alam yang baru diresmikan pada Bulan Nopember 2017. Buper Pasir Batang memiliki keindahan alam yang bervariatif dengan suasana pegunungan yang khas. Buper Pasir Batang dikelola oleh Kompepar Karangsari dengan jumlah anggota sebanyak 26 (dua puluh enam) orang.

Buper Pasir Batang merupakan objek wisata alam baru dengan berbagai macam daya tarik yang unik. Keragaman potensi objek dan daya tarik wisata alam di Buper Pasir batang antara lain camping ground, flora, fauna, bentang alam, dan kondisi sosial budaya masyarakat. Keragaman potensi wisata tersebut berpotensi menarik minat pengunjung untuk melakukan aktivitas wisata alam di Buper Pasir Batang.

Buper Pasir Batang termasuk dalam pengelolaan kawasan konservasi Taman Nasional Gunung Ciremai. Aktivitas wisata di Buper Pasir Batang sudah seharusnya menjadi bagian strategi konservasi untuk meningkatkan keberlanjutan ekologi, ekonomi, dan sosial budaya. Sehingga wisata yang dapat dikembangkan adalah 
berbentuk ekowisata. Salah satu upaya untuk mencapai tujuan ekowista adalah kegiatan interpretasi.

Kompepar Karangsari merupakan pengelola teknis Buper Pasir Batang. Peningkatan kapasitas kompepar dalam usaha pengelolaan untuk mewujudkan manfaat ekologi, ekonomi, dan sosial budaya adalah dengan kegiatan interpretasi. Tujuan kegiatan interpretasi adalah untuk menyampaikan berbagai keunikan objek yang dimiliki Buper Pasir Batang dan meningkatkan minat pengunjung untuk datang dan menikmati, merasakan, dan ikut serta melestarikan berbagai objek di Buper Pasir Batang. Berdasarkan uraian diatas dapat disimpulkan beberapa permaslah yang dihadapi mitra dalam pengelolaan Buper Pasir Batang, yaitu :

1. Buper Pasir Batang merupakan objek wisata baru, sehingga diperlukan usaha pemasaran objek dan daya tariknya untuk menarik minat pengunjung

2. Buper Pasir Batang berada dalam kawasan konservasi Taman Nasional Gunung Ciremai, sehingga berbagai aktivitas yang dilakukan harus sinergi dengan tujuan pengelolaan kawasan konservasi

3. Kegiatan interpretasi merupakan salah satu usaha untuk menarik minat pengunjung dan selaras dengan tujuan pengelolaan kawasan konservasi. Sehingga diperlukan peningkatan kapasitas mitra mengenal objek interpretasi, menetukan media interpretasi, dan mengelola media interpretasi.

\section{METODE PELAKSANAAN}

Pelaksanaan kegiatan Peningkatan Kapasitas Media Sosial Interpretasi bagi Pengelola Bumi Perkemahan Pasir Batang dilakukan dengan beberapa tahapan, yaitu :

1. Persiapan;

a. Pengumpulan data terkait objek dan daya tarik wisata

b. Pelatihan/Peningkatan kapasitas Kompepar untuk mengenal dan menginterpretasikan objek daya tarik wisata

2. Analisis Potensi Media Sosial; Analisis karakteristik media sosial dilakukan untuk menentukan media sosial yang sesuai digunakan sebagai media interpretasi dalam mendukung kegiatan ekowisata di Buper Pasir Batang. Penentuan tersebut dilakukan berdasarkan aspek atau karakteristik: basis peralatan yang digunakan untuk dapat mengakses, konten yang dapat disajikan, fungsi dan keunggulan media sosial, dan cakupan atau jumlah pengguna media sosial (monthly active users).

3. Desain Media Sosial; Desain media sosial interpretasi merupakan rancangan penggunaan media sosial untuk kegiatan interpretasi. Desain media sosial interpretasi meliputi visualisasi penggunaan (pesan) dan rekomendasi pengelolaan. Visualisasi tersebut berupa tampilan penggunaan media sosial dan cara penyampaian pesan (tata letak dan komposisi).

4. Pengeloaan Media Sosial; Pengelolaan media sosial akan dilakukan langsung oleh operator dari Kompepar, sehingga pada tahap ini akan dilakukan pelatihan pengelolaan media sosial bagi operator dari Kompepar. 


\section{HASIL DAN PEMBAHASAN}

\section{Potensi Objek Interpretasi}

\subsection{Potensi Keanekaragaman Hayati}

Keanekaragaman hayati sebagai objek interpretasi digolongkan kedalam 2 (dua) kriteria, yaitu flora dan fauna. Berdasarkan sejarah pengelolaanya, Buper Pasir Batang pada awalnya merupakan hutan produksi yang dikelola oleh Perum Perhutani KPH Kuningan dengan kelas perusahaan pinus. Saat ini berdasarkan tata ruang kawasan TNGC Buper Pasirbatang termasuk pada zona pemanfaatan. Sehingga dari sisi keanekaragaman flora tidak cukup beragam dan didominasi oleh jenis Pinus (Pinus merkusii). Secara keseluruhan hanya dijumpai 12 jenis vegetasi pada habitus pohon di Buper Pasirbatang seperti yang ditamoilkan pada Tabel 2.

Tabel 2. Daftar Jenis Vegetasi Asli Setempat di Areal Buper Pasir Batang

\begin{tabular}{cll}
\hline No. & \multicolumn{1}{c}{ Nama Lokal } & \multicolumn{1}{c}{ Nama Botani } \\
\hline 1. & Aren, kawung & Arengga piñata \\
2. & Huru Pingku & Dysoxylum gaudichaudianum \\
3. & Beunying & Ficus fistulosa \\
4. & Kihampelas & Ficus pisiphera \\
5. & Kondang & Ficus variegate \\
6. & Mara & Macaranga rhicinoides \\
7. & Cempaka & Magnolia candolei \\
8. & Jengkol & Pithecolobium lobatum \\
9. & Pakis & Alsophila contaminans Wall. \\
10. & Kaliandra Merah & Caliandra callothyrsus \\
11. & Kalindra Putih & Caliandra zapoteca \\
12. & Kasemek & Diospyros kakii \\
\hline
\end{tabular}

Berdasarkan informasi masyakat dari sisi keanekaragam fauna hanya dijumpai 19 jenis burung, 8 mamalia, dan 4 reptil. Selain tegakan pohon pinus, yang menjadi daya tarik dan berpotensi sebagai objek interpretasi di Buper Pasir Batang adalah jenis Pakis purba, yaitu Alsophila contaminans Wall.dan Kesemek (Diospyros kakii) yang tumbuh secara mengelompok pada beberapa bagian Buper.

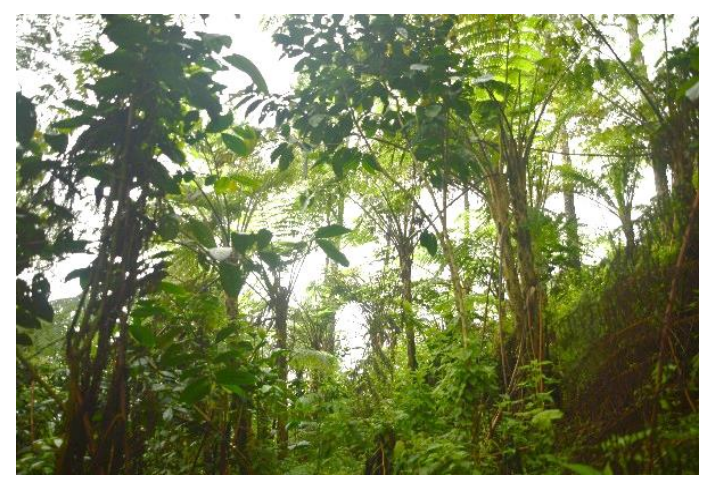

(a)

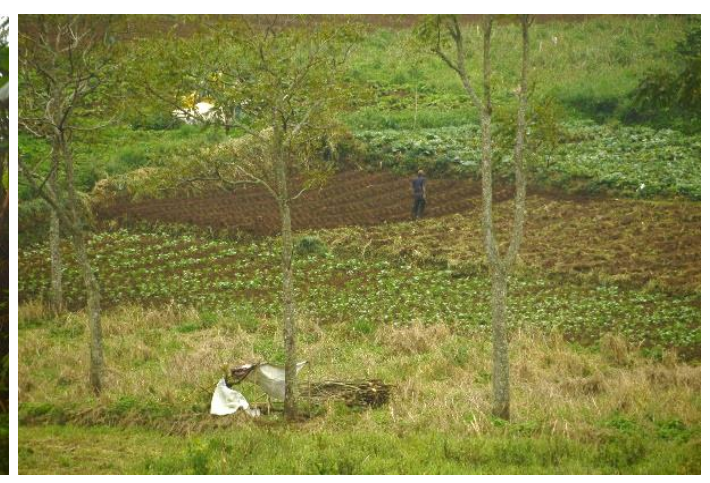

(b)

Gambar 1. Potensi keanekaragaman hayati: (a) Pakis; (b) Kesemek 


\subsection{Potensi Sejarah dan Budaya}

Buper Pasir Batang dan sekitarnya menyimpan potensi sejarah dan budaya yang cukup menarik. Sejarah dan budaya yang terdapat di Buper Pasir Batang legenda Lutung Kasarung di Bukit Pasir Batang, makam tokoh penyebar islam Sech Marmagati serta situs peninggalan prasejarah Batu Lingga. Khusus situs Batu Lingga adalah merupakan situs peninggalan prasejarah dengan pusat peninggalah prasejarah terletak di Taman Purbakala Cipari Kec. Cigugur, Kabupaten Kuningan.

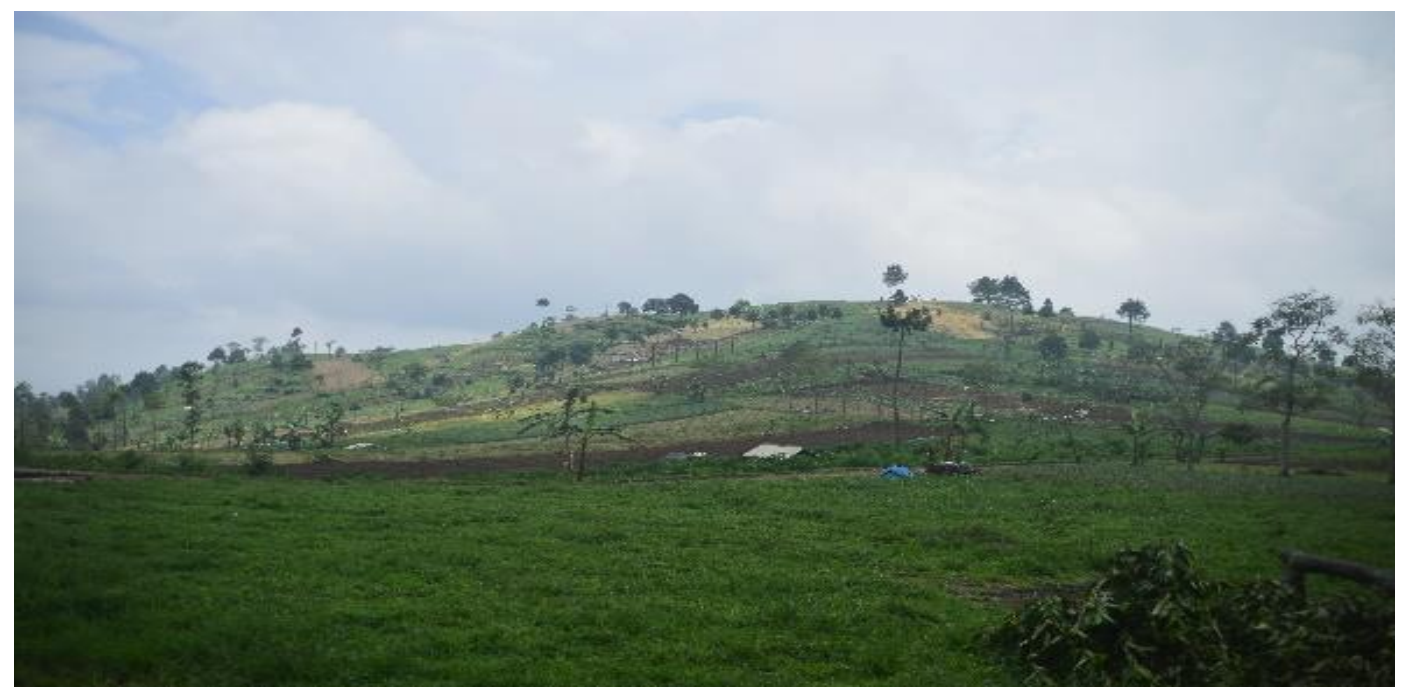

Gambar 2. Pasir Batang dengan legenda Lutung Kasarung

\subsection{Potensi Lansekap}

Buper Pasir Batang menawarkan suasana alam khas pegunungan dengan ketinggian tempat lebih dari 1.000 mdpl. Selain kegiatan berkemah dibawah tegakan pohon pinus yang asri dan kabut gunung yang serig menyelimuti, Buper Pasir Batang juga menawarkan pemandangan alam deng view yang menarik. Aktivitas lain yang dapat dilakukan di lokasi Ekowisata Pasir Batang antara lain agrotourism, hiking, bersepeda, dan wisata sejarah. Sementara itu fasilitas yang tersedia di Buper Pasir batang adalah mushala, toilet, penerangan, fasilitas permainan, spot photo, dan lain-lain. Kedepan pada lokasi ini akan dibangun fasiltas flyingfox sepanjang $1 \mathrm{~km}$ dari bukit Pasir Batang ke area camping ground.

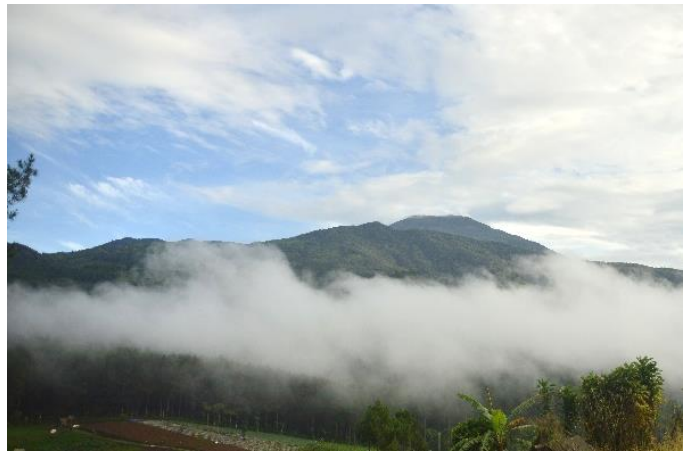

(a)

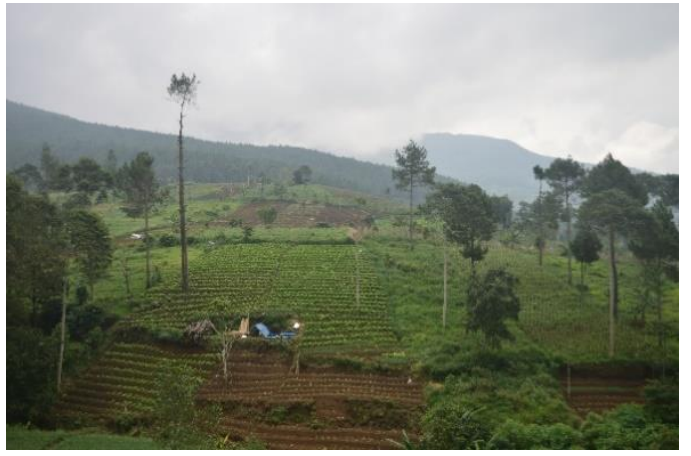

(b)

Gambar 3. Potensi lansekap: (a) Lansekap Buper; (b) Lansekap Pertanian 


\section{Potensi Media Sosial Sebagai Media Interpretasi}

Pesatnya perkembangan teknologi pada dekade terakhir telah memfasilitasi terjadinya transformasi dalam cara berkomunikasi antara seseorang dengan yang lainnya, yaitu melalui jejaring media sosial. Prospek pengguna media sosial (jejaring sosial) yang tiap tahunnya mengalami peningkatan memungkinkan cakupan penerima kegiatan interpretasi melalui media sosial semakin banyak seiring berjalannya waktu.

Sampai saat ini, media sosial yang telah ada berjumlah 1.100 (Smith 2018). Penelitian ini menggunakan 115 media sosial terbaik sesuai tren dan kegunaannya, sebagai bentuk perwakilan (10\%) dari media sosial yang ada. Media sosial dengan kegunaan komunikasi memiliki potensi terbaik sebagai media sosial interpretasi dibandingkan dengan kegunaan lainnya karena pada proses kegiatan interpretasi terjadi suatu proses komunikasi antara sumber dengan penerima informasi (Canada 1976 dalam Veverka 1998; Muntasib 2003). Media sosial yang paling mendominasi secara global adalah Facebook dan pada kategori komunikasi yang memiliki jumlah pengguna terbanyak adalah Facebook, yaitu sebanyak 2.072 miliyar pengguna aktif per bulan .

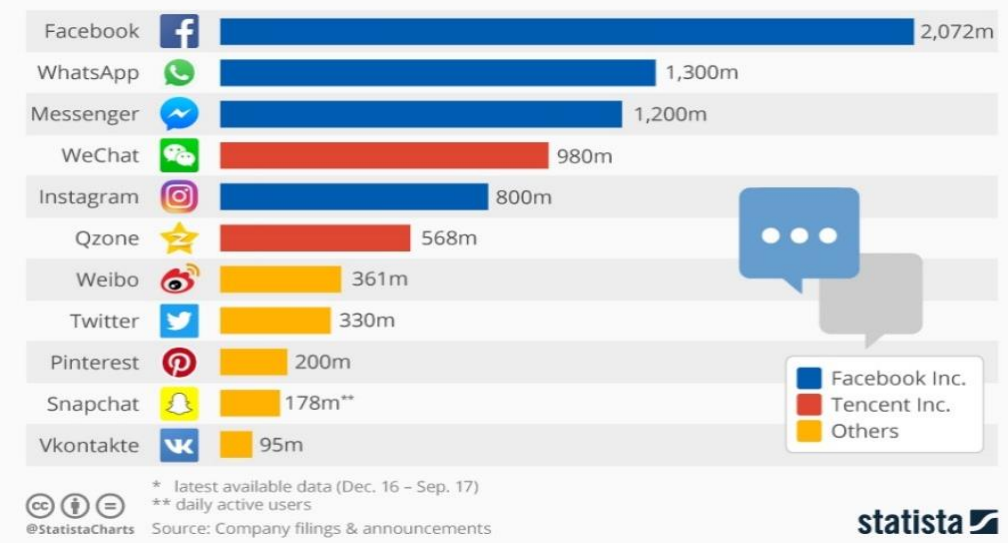

Gambar 4. Pengguna Aktif per Bulan (monthly active users) Media Sosial Sumber; https://www.statista.com

Komunikasi pada Facebook memang tidak selalu dilakukan secara tatap muka langsung, namun kemampuan komunikasi dari mulut ke mulut tetap dapat terjadi. Veverka (1998) menyebutkan bahwa kemampuan cerita dari mulut ke mulut memiliki peranan penting dalam ekowisata karena pada dasarnya ekowisata produk utamanya adalah pengalaman yang diperoleh oleh pengunjung. Haditia (2012) juga menyatakan bahwa motivasi pengunjung datang ke tempat tujuan wisata beberapa alasannya adalah diajak oleh teman dan mendengar cerita dari teman.

\section{Desain Media Sosial sebagai Media Interpretasi}

Facebook dipilih sebagai media sosial yang digunakan untuk interpretasi Buper Pasir Batang berdasarkan potensinya dan karakter pengunjung maupun pengguna media sosial. Penggunaannya sebagai media interpetasi mengikuti ketentuan dan kebijakan dari Facebook serta untuk mewakili Buper Pasir Batang secara resmi dapat menggunakan Facebook sebagai sebuah halaman (fan page). Agar dapat menghasilkan desain media interpretasi yang baik, selain pemilihan media perlu diperhatikan pula 
pesan, pengelolaan, pemasaran, dan perawatan/teknisi (Brochu 2014). Karena itu, selain tampilan media sosial, desain media sosial interpretasi juga memperhatikan pesan yang akan disampaikan, serta pengelolaannya, termasuk di dalamnya pemasaran dan perawatan media sosial tersebut.

\subsection{Tampilan Media Sosial Interpretasi}

Halaman di Facebook dapat menampilkan glosarium halaman, foto dan video, hal yang menarik atau minat, acara yang akan datang, dan kiriman dari pengguna media sosial yang turut aktif di halaman. Suatu halaman terdiri dari nama dan kategori halaman, foto profil, foto sampul, deskripsi/tentang halaman, kronologi, foto album dan video, menu (tombol) suka, panel pengelolaan (termasuk menu promosikan halaman, hanya bagi pengelola), serta terdapat pilihan tautan yang disesuaikan dengan keinginan pengelola, dan pilihan Bahasa (Gambar 5).

\subsection{Pesan (materi) yang disampaikan}

Pesan yang disampaikan dalam kegiatan interpretasi adalah materi potensi obyek interpretasi yang telah dipilih sebagai obyek interpretasi pengantar. Obyek interpretasi pengantar didapatkan dari skoring obyek interpretasi yang termasuk dalam kelas prioritas tinggi dan/atau melihat urgensi pesan untuk disampaikan. Pesan yang disampaikan mengungkapkan makna/interaksi sumberdaya, yaitu berupa status kelangkaan, keunikan, peristiwa musiman, keaslian, peranan (memiliki nilai tertentu), manfaatnya bagi manusia, dan/atau kemudahan ditemukannya obyek tersebut. Pesan yang disampaikan merupakan pesan yang menceritakan tentang hal yang dapat dilihat atau dijadikan pengalaman (Trapp et. al. 1994) dan mengandung pendidikan dan bertujuan untuk mengungkap makna dan hubungan (Tilden 1957).

Pesan yang disampaikan adalah semua objek interpretasi yang menjadi daya tarik di Buper Pasir Batang, seperti legenda lutung kasarung, dan lainya.

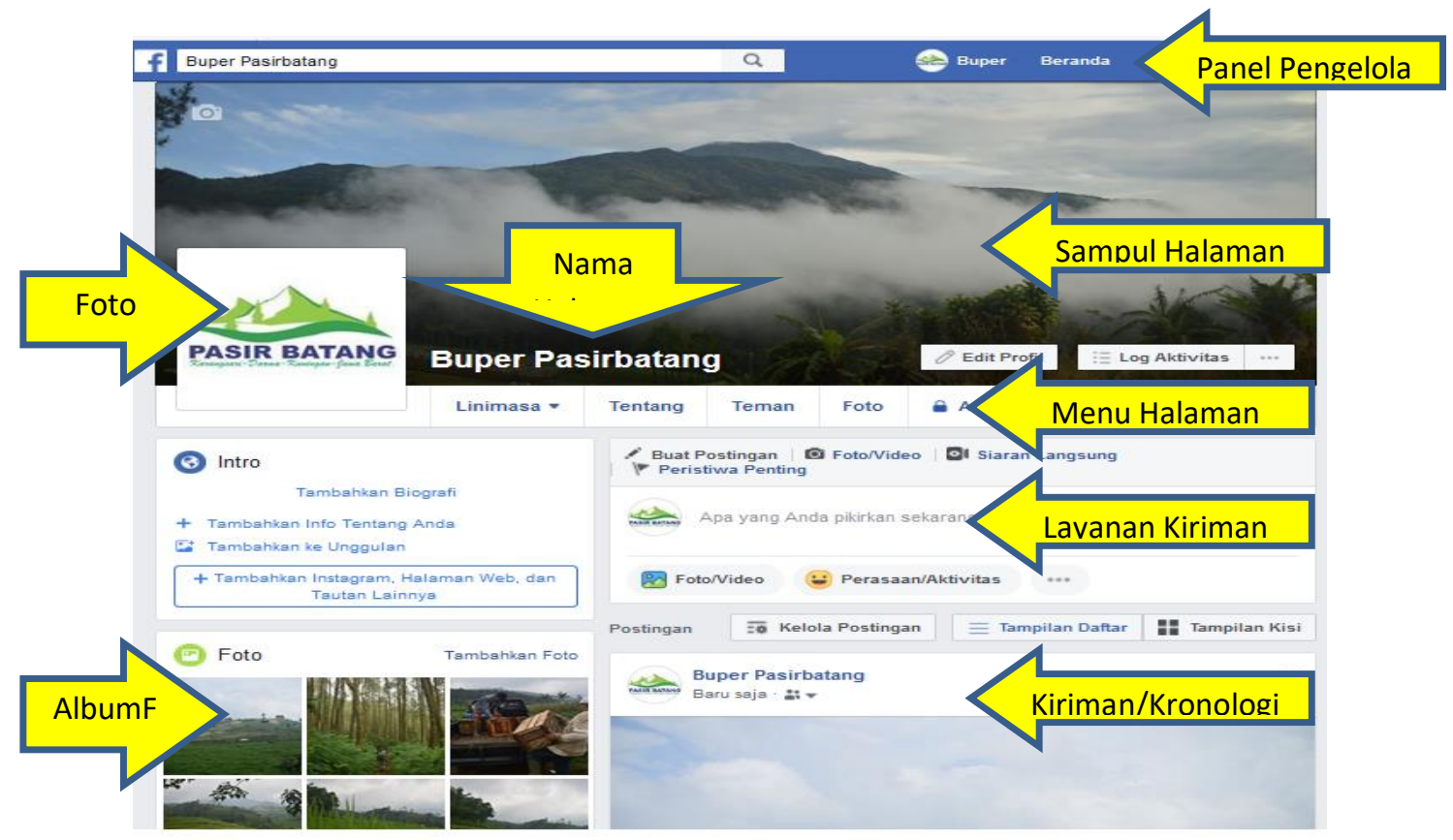

Gambar 5. Tampilan halaman Facebook untuk kegiatan interpretasi 


\subsection{Cara Penyampaian Pesan}

Penyampaian pesan dilakukan secara cepat, efektif, dan dramatis. Penyampaian secara cepat dan efektif dilakukan menggunakan aturan 3 detik, 30 detik, atau 3 menit sehingga dalam waktu tersebut penerima pesan diharapkan sudah dapat mengerti atau mendapatkan pesan yang tersirat (adaptasi dari Trapp et. al. 1994). Penyampaian secara dramatis maksudnya adalah pesan dibuat menjadi mengesankan atau mengharukan, sehingga emosi dari pembaca dapat tergugah. Emosi tersebut dapat berupa senang, bangga, atau sedih. Rasa senang dan bangga dalam membaca interpretasi diharapkan dapat membuat pembaca dapat menikmati bacaan, mempelajari dan menumbuhkan rasa memiliki, sedangkan rasa sedih dimaksudkan menggugah rasa kehilangan akan obyek sehingga kesadaran terhadap obyek dapat meningkat. Pesan disampaikan secara ringkas dan dapat memprovokasi pembaca untuk turut serta sesuai harapan/tujuan pesan yang disampaikan.

Desain dan tata letak pesan pada sebuah foto atau ilustrasi dapat tertata langsung di konten atau terpisah. Pemilihan huruf, warna dan komposisi lainnya juga dapat mempengaruhi ketertarikan pembaca. Hal tersebut didukung oleh pernyataan Muntasib (2003) yang menyatakan bahwa interpretasi merupakan seni dalam menjelaskan keadaan lingkungan sehingga penyampaianpesan dapat dikreasikan agar pesan dan foto/ilustrasi terlihat harmonis. Pesan melalui video dapat disampaikan pada klimaks sampai akhir video. Awal video berupa pendahuluan untuk menuju pesan sedangkan akhir video dapat berupa kesimpulan pesan untuk memperkuat penyampaian pesan.

\subsection{Pengelolaan Pesan}

Pengelolaan yang perlu diperhatikan dalam media sosial interpretasi adalah pembaharuan kabar/pesan. Kabar maupun pesan pada media sosial memang dapat tersebar secara cepat dan menyeluruh, yang merupakan keunggulan media sosial, tetapi bila pembaharuan kabar/pesan tidak terkelola dengan baik maka dapat menjadi kelemahan bagi penggunanya. Karena karakteristik pengguna media sosial yang dapat melihat pembaharuan tiap saat, maka pembaharuan kabar yang tidak teratur dan memiliki jenjang yang lama antara suatu pembaharuan kabar dengan lainnya akan dapat membuat pengguna media sosial meninggalkan halaman. Waktu penyampaian pesan juga sangat berpengaruh dengan kemungkinan pesan terbaca dengan seksama oleh penerima. Bila waktu terbaik untuk menyampaikan pesan diketahui, maka dapat diketahui pula jangkauan maksimal ketika membagikan pesan untuk dapat memastikan pengguna melihat pesan yang dibagikan. Bila pengguna memulai berkomentar, suka, dan/atau membagikan kepada temannya, maka penyebaran pesan tersebut menjadi semakin baik.

Pengelolaan interpretasi pada Facebook dapat dilakukan oleh organisasi yang sudah ada saat ini, yaitu Kompepar Karangsari. Akan tetapi, mengingat kebutuhan pembaharuan pesan dan pengelolaan media sosial yang intensif, maka diperlukan adanya staf (minimal satu) yang fokus/khusus mengelola media sosial interpretasi dan siap memperbaharui kabar atau memberi tanggapan setiap saat sebagai bentuk 
pelayanan.Agar pengelolaan tersebut dapat berjalan selaras antara satu dengan yang lain maka dapat diadakan sosialisasi maupun peningkatan mutu sumberdaya manusia (SDM) sehingga staf yang lain juga dapat berkontribusi dalam membagikan pesan maupun berbagi cerita.

\section{Peningkatan Kapasitas Anggota Kompepar}

Peningkatan kapasitas anggota Kompepar dalam menngunakan media sosial untuk interpretasi objek dan daya tarik wisata di Buper Pasir Batang dibagi kedalam beberapa tahap, yaitu tahap sosialisai, pelatihan interpretasi, dan pengelolaan media sosial untuk interpretasi.

Tahapan yang telah dilaksanakan pada kegiatan ini baru pada tahap sosialisasi dan pelatihan interpretasi. Sementara tahapan pengelolaan media sosial interpretasi akan dilakukan pada kegiatan selanjutnya.
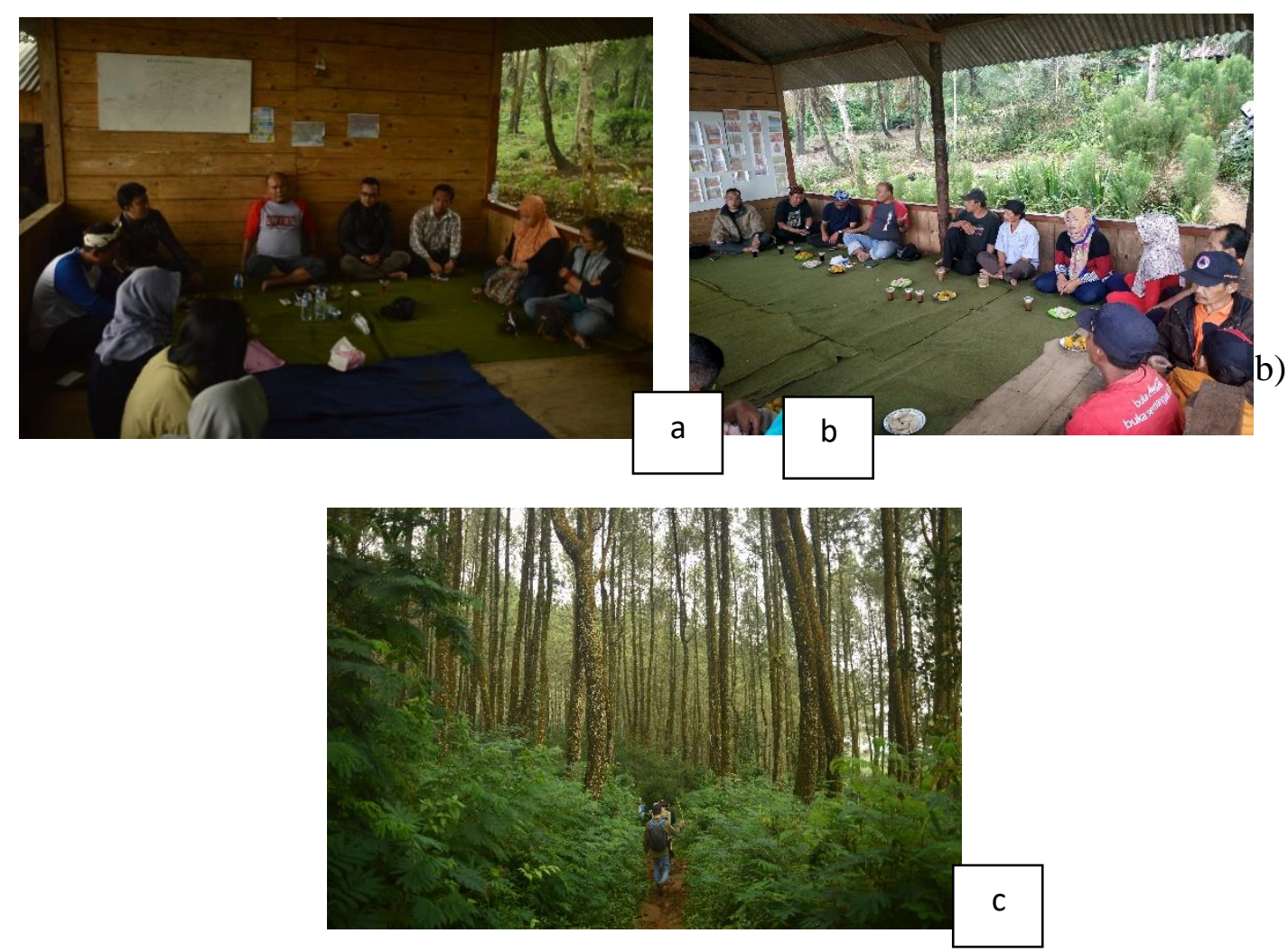

(c)

Gambar 6. Sosialisasi dan Pelatihan Interpretasi: (a) Sosialisasi; (b) Pelatihan Interpretasi (Teori); (c) Pelatihan Interpretasi (Praktek)

\section{Capaian Lainya}

Selain capain yang telah disebutkan diatas, yaitu analisis jenis dan desain media sosial interpreasi, sosialisai, dan pelatihan interpretasi (teori dan praktek). Capain lainya dari kegiatan ini adalah publikasi wisata Buper Pasir Batang pada media cetak, yaitu pada majalah Green Indonesia No. 18/Tahun IV/2018 (ISSN 246o1934). 

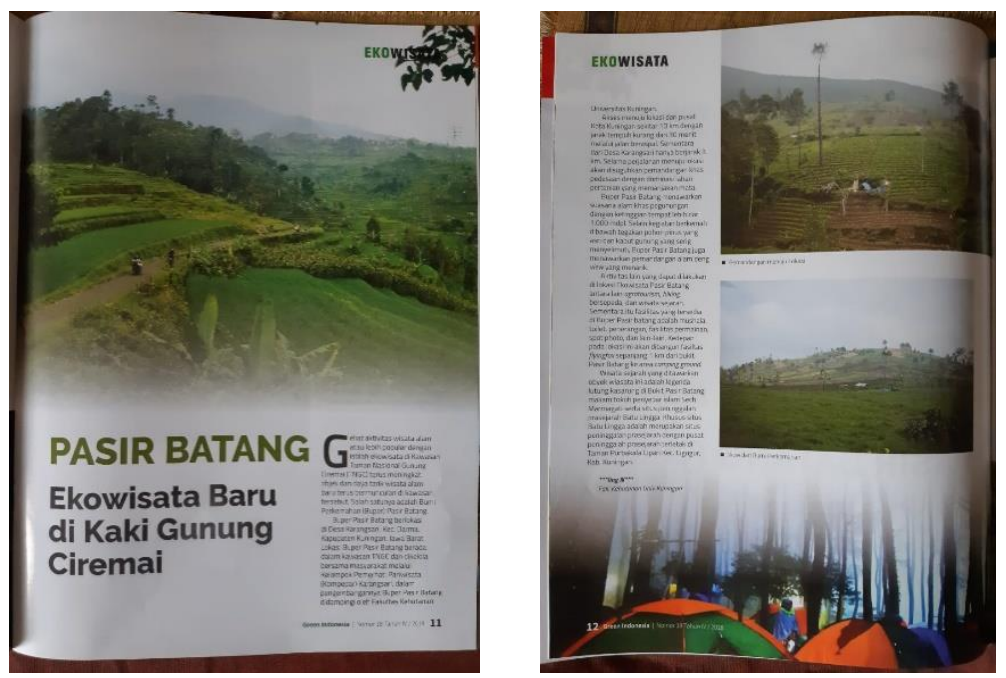

Gambar 7. Publikasi Buper Pasir Batang Pada Media Cetak Nasional (Majalah Green Indonesia No. 18/Tahun IV/2018

\section{SIMPULAN}

Berdasarkan hasil pembahasan tersebut diatas maka penulis dapat menyimpulkan, yaitu antara lain :

1. Media sosial yang tepat digununakan untuk media interpretasi Buper Pasir Batang adalah Facebook;

2. Desain dana kun media sosial (facebook) telah tersedia;

3. Kapasitas interpretasi objek anggota Kelompok Penggiat Pariwisata Karangsari sebagai pengelola Buper Pasir Batang meningkat karena telah mengikuti pelatihan interpretasi objek baik materi ataupun praktek Masyarakat dengan konsep "Ecovillage".

\section{SARAN}

Salah satu tahapan dalam kegiatan ini belum dilaksanakan, yaitu penggunaan dan pengelolaan media sosial untuk interpretasi. Sehingga perlu dilanjutkan pada kegiatan berikutnya.

\section{UCAPAN TERIMA KASIH}

Penulis ucapkan terima kasih kepada telah diberikan sehingga terselenggaranya kegiatan pengabdian ini. Kegiatan pengabdian ini dibiayai Universitas Kuningan Berdasarkan Surat Persetujuan Rektor No. 81.39/SPK/LPPM.PM-UNIKU/KNG/2018 Tanggal 8 Juni 2018. 


\section{DAFTAR PUSTAKA}

Brochu L. 2014. Interpretive Planing: The 5-M Model for Successful Planing Projects. Fort Collins (US): NAI, National Association for Interpretation.

Haditia M. 2012. Perencanaan intepretasi di kawasan hutan dengan tujuan khusus (KHDTK) Cikampek, Kecamatan Cikampek, Kabupaten Karawang, Provinsi Jawa Barat [skripsi]. Bogor (ID): Institut Pertanian Bogor.

Kaplan AM, Haenlein M. 2010. Users of the world, unite! The challenges and opportunities of social media. Business Horizons, 53(1): 59-68.

Lindsay BR. 2011. Social Media and Disasters: Current Uses, Future Options, and Policy Considerations. Amerika (US): CRS Report for Congress.

Muntasib EKSH. 2003. Interpretasi Wisata Alam. Bogor (ID): Laboratorium Rekreasi Alam, Departemen Konservasi Sumberdaya Hutan, Fakultas Kehutanan, Institut Pertanian Bogor.

Roni Nursyamsu. 2018. Pelatihan Peningkatan Kapasitas Pemuda Dan Pembuatan Program Kerja Pada Organisasi Pemuda Desa Cibinuang, Kabupaten Kuningan, Empowerment : Jurnal Pengabdian Masyarakat, E-Issn 2598-2052 Vol. 01 Nomor 01. 2018. 37- 44.

Sharpe GW. 1982. Interpreting the environment (2nd edition). Amerika (US): John Willey \& Sons, Inc.

Smith C. 2018. How many people use facebook, twitter, pinterest, and 1000+ of the top social media, apps, \& services. [internet]. [diunduh pada 2018Agustus 20]. Tersedia pada: http://expandedramblings.com/index.php/resource-how-manypeople-use-the-top-social-media/

Soekartawi, Suhardjono, Hartanto T, Ansharullah A. 1995. Meningkatkan rancangan instruksional (instructional design): untuk memperbaiki kualitas belajar mengajar. Jakarta (ID): Raja Grafinda Persada.

Tilden, F. 1957. Interpreting our heritage: principles and practices for visitor services in parks, museums, and historic places. New York (US): The University of North Carolina Press.

Trapp S, Gross M, Zimmerman R. 1994. Signs, trail, and wayside exhibits: connecting people and places, 2nd edition. Stevens Point (US): University of Wisconsin Stevens Point (UW-SP) Foundation Press, Inc.

Veverka JA. 1998. Interpretive master planning. California (US): Acorn Naturalists. 